Article

\title{
Application of ${ }^{1} \mathrm{H}$ and ${ }^{13} \mathrm{C}$ NMR Fingerprinting as a Tool for the Authentication of Maltese Extra Virgin Olive Oil
}

\author{
Frederick Lia ${ }^{1, *(\mathbb{D})}$, Benjamin Vella ${ }^{1}$, Marion Zammit Mangion ${ }^{2} \mathbb{D}$ and Claude Farrugia ${ }^{1} \mathbb{D}$ \\ 1 Department of Chemistry, University of Malta, 2080 MSD Msida, Malta; ben.vella.16@um.edu.mt (B.V.); \\ claude.farrugia@um.edu.mt (C.F.) \\ 2 Department of Physiology and Biochemistry, University of Malta, 2080 MSD Msida, Malta; \\ marion.zammit-mangion@um.edu.mt \\ * Correspondence: fredericklia@gmail.com
}

Received: 24 April 2020; Accepted: 22 May 2020; Published: 26 May 2020

\begin{abstract}
The application of ${ }^{1} \mathrm{H}$ and ${ }^{13} \mathrm{C}$ nuclear magnetic resonance (NMR) in conjunction with chemometric methods was applied for the discrimination and authentication of Maltese extra virgin olive oils (EVOOs). A total of 65 extra virgin olive oil samples, consisting of 30 Maltese and 35 foreign samples, were collected and analysed over four harvest seasons between 2013 and 2016. A preliminary examination of ${ }^{1} \mathrm{H}$ NMR spectra using unsupervised principle component analysis (PCA) models revealed no significant clustering reflecting the geographical origin. In comparison, PCA carried out on ${ }^{13} \mathrm{C}$ NMR spectra revealed clustering approximating the geographical origin. The application of supervised methods, namely partial least squares discriminate analysis (PLS-DA) and artificial neural network (ANN), on ${ }^{1} \mathrm{H}$ and ${ }^{13} \mathrm{C}$ NMR spectra proved to be effective in discriminating Maltese and non-Maltese EVOO samples. The application of variable selection methods significantly increased the effectiveness of the different classification models. The application of ${ }^{13} \mathrm{C}$ NMR was found to be more effective in the discrimination of Maltese EVOOs when compared to ${ }^{1} \mathrm{H}$ NMR. Furthermore, results showed that different ${ }^{1} \mathrm{H}$ NMR pulse methods can greatly affect the discrimination of EVOOs. In the case of ${ }^{1} \mathrm{H}$ NMR, the Nuclear Overhauser Effect (NOESY) pulse sequence was more informative when compared to the zg30 pulse sequence, since the latter required extensive spectral manipulation for the models to reach a satisfactory level of discrimination.
\end{abstract}

Keywords: extra virgin olive oil; authentication; chemometrics; proton NMR; carbon NMR; machine learning; artificial neural networks; PLS-DA

\section{Introduction}

Several international organisations, including the European Union through its directives (EC No. 2568/1991 and its amendments) [1] and the International Olive Oil Council (COI/T.15/NC No. 3/ Rev 6) [2], have been at the vanguard in the development of methods and establishing limits for physicochemical parameters of extra virgin olive oil (EVOO) to protect against frauds. The typical approach relies on comparison of the chemical composition with official limits, as it is expected that the presence of adulterants will modify the concentration of these constituents. Nonetheless, this procedure may be inadequate, especially for oils which are classified as 'virgin' but do not conform to official limits of certain constituents due to local climatic or soil peculiarities [3]. Furthermore, these methodologies do not address the problem of geographical traceability and tend to be rather time-consuming with a very low throughput.

During the last decade, nuclear magnetic resonance (NMR) spectroscopy has been shown to be highly effective in the study of oils of vegetable origin [4-8]. In 1999, Vlahov [9] proposed NMR 
spectroscopy as a new analytical tool to compete with the existing methods for studying olive oil chemistry. Among the vast applications of NMR spectroscopy to the study of EVOO, target analysis of triacylglycerides, fatty acids, unsaturated fatty chains for quantification, seed oil adulteration, and degradation of EVOOs encompass some of the techniques that could employ the use of NMR. Furthermore, NMR spectroscopy could also be extended to the study of minor constituents including phenolic compounds, sterols, and phospholipids for both detection and quantification of markers for geographical origin and cultivar information. The main methods used in NMR include ${ }^{1} \mathrm{H}$ and ${ }^{13} \mathrm{C}$ NMR spectroscopy as reviewed by a number of authors [9-14] together with ${ }^{31} \mathrm{P}$ NMR as employed by Spyros and Dais [15]. Apart from target-based analytical approaches, NMR metabolic fingerprinting [16-18] employs the use of whole NMR spectral data to classify a relevant number of samples according to their origin, harvest, and age. In most cases, fingerprinting analysis is used in conjunction with sophisticated statistical and mathematical procedures.

${ }^{1} \mathrm{H}$ NMR has been much more widely used in the field of olive oil chemistry than ${ }^{13} \mathrm{C}$ NMR. While requiring more concentrated samples than ${ }^{1} \mathrm{H}$ NMR, ${ }^{13} \mathrm{C}$ NMR spectra have a much wider radiofrequency range. Coupled with proton decoupling techniques, this leads to sharp spectra which rarely have overlapping carbon peaks, allowing easy detection of impurities and making the peaks readily interpretable. The main disadvantage in ${ }^{13} \mathrm{C} N \mathrm{NMR}$ is the long acquisition times which reduces the sample throughput, unlike ${ }^{1} \mathrm{H}$ NMR which takes around $10 \mathrm{~min}$ for the entire run to be completed. Preedy and Watson [19] suggest that each type of NMR spectroscopy could be used for a different type of analysis into the composition of olive oil-the ${ }^{13} \mathrm{C}$ technique is useful in characterisation of the genotype of the oil, while the ${ }^{1} \mathrm{H}$ NMR technique is more suited to geographical characterisation of the oils.

The combination of ${ }^{1} \mathrm{H}$ and ${ }^{13} \mathrm{C}$ NMR fingerprinting with multivariate analysis provides a promising approach to studying the profile of olive oils in relation to their geographical origin. The Maltese olive oil industry makes an interesting case, as the industry has only recently been regenerated using an indigenous olive stock. Considering the small state of the market, mislabeled EVOO originating from other countries sold as Maltese EVOO could severely impede the growth of the industry, with severe negative economic repercussions. Recent studies have shown that Maltese EVOOs have a significantly different phenolic composition and mineral composition [20-22]. In this study, a variety of olive oils selected from different areas around the Maltese islands and countries around the Mediterranean were studied. No data is present in the literature regarding the use of ${ }^{13} \mathrm{C}$ and ${ }^{1} \mathrm{H}$ NMR for the authentication of Maltese EVOOs. The aim of this study was to explore the use of ${ }^{13} \mathrm{C}$ NMR and ${ }^{1} \mathrm{H}$ NMR (specifically ${ }^{1} \mathrm{H}$ zg30 and ${ }^{1} \mathrm{H}$ NOESY), in conjunction with chemometrics in order to differentiate the Maltese EVOOs from other EVOOs derived from other countries within the Mediterranean region, thus developing an easy and cost-saving verification method for the origin of EVOOs from the Maltese islands ensuring olive oil chain sustainability.

\section{Materials and Methods}

\subsection{Sample Preparation}

For this preliminary study, a total of 65 extra virgin olive oil samples were collected from the Maltese islands over four harvest seasons from 2013-2016 and from other neighboring Mediterranean countries. The cultivars used in this study and their country of origin can be seen in Table S1. The samples were all taken from different oil producers to cover a representative sample of the Maltese islands in terms of pedological and microclimatic conditions, whilst also accounting for manufacturing techniques and the different presses employed. Foreign olive oils obtained were bought with a protected designation of origin in order to ensure traceability of the product. All the samples were stored at $4{ }^{\circ} \mathrm{C}$ in the absence of light prior to the analysis. The samples were preheated to $35^{\circ} \mathrm{C}$ in a water bath for $1 \mathrm{~h}$ and mixed to ensure homogeneity. For ${ }^{1} \mathrm{H}$ NMR, $20 \mu \mathrm{L}$ of the EVOO were placed in $5 \mathrm{~mm}$ NMR tubes and dissolved in $700 \mu \mathrm{L}$ of deuterated chloroform, followed by the addition of $20 \mu \mathrm{L}$ 
of deuterated DMSO and vortex mixing for $20 \mathrm{~s}$. For ${ }^{13} \mathrm{C}$ NMR, $440 \mu \mathrm{L}$ of sample was dissolved in $420 \mu \mathrm{L}$ of deuterated chloroform without the addition of DMSO [23].

\section{2. ${ }^{1} \mathrm{H}$ and ${ }^{13} \mathrm{C}$ NMR Spectra Acquisition}

The analysis was performed on a model AVANCE III $500 \mathrm{MHz}$ NMR spectrometer equipped with a $5 \mathrm{~mm}{ }^{1} \mathrm{H} / \mathrm{D}$-BB probehead with z-gradient, automated tuning and matching accessory, and a BTO-2000 accessory for temperature control (Bruker BioSpin GmbH, Rheinstetten, Germany). Samples were measured at $300.0 \mathrm{~K}$ after a $5 \mathrm{~min}$ resting period for temperature equilibration. NMR spectra were acquired using Topspin 3.5 (Bruker). Automated tuning and matching, locking and shimming using the standard Bruker routines, ATMA (automatic tuning and matching in automatic mode), LOCK (frequency-field lock to offset the effect of the natural drift of the NMR's magnetic field B0) and TopShim, were used to optimise the NMR conditions. Samples were analysed using the zgpg30 pulse method for ${ }^{13} \mathrm{C}$ NMR, while the zg30 and NOESY 1D noesypr1d NMR pulse sequence using a standard presaturation were used for ${ }^{1} \mathrm{H}$ NMR. Every extract sample was run twice with a ${ }^{1} \mathrm{H} N \mathrm{NR}$ standard single pulse experiment $\mathrm{zg} 30$ for 100 scans. The samples were run twice automatically under the control of ICON-NMR. Each run had two prior dummy scans, resulting in 65,536 data points with a resolution of $0.305 \mathrm{~Hz}$ acquired with an acquisition time and a relaxation delay time of 3.27 and $4 \mathrm{~s}$, respectively. The $90^{\circ}$ flip angle for free induction decay was adjusted to $10 \mu \mathrm{s}$. In the case of one-dimensional Nuclear Overhauser Effect spectroscopy, 100 scans were acquired, each run having two dummy scans, which resulted in 32,768 data points with a resolution of $0.489 \mathrm{~Hz}$, acquired with an acquisition time and relaxation time of $\sim 2.04$ and $4 \mathrm{~s}$, respectively. In the case of ${ }^{13} \mathrm{C} N M R, 250$ scans were recorded for each sample, with an acquisition time of $21 \mathrm{~s}$ to allow sufficient time for complete relaxation of ${ }^{13} \mathrm{C}$ nuclei between scans. The acquisition delay was set at $2 \mathrm{~s}$. The receiver gain was set at 203 , and the temperature was locked at $298.0 \mathrm{~K}$ by means of a BTO-2000 accessory. Broadband $1 \mathrm{H}$ decoupling techniques were employed. The above parameters and settings could run samples with a turnover time of $1 \mathrm{~h}$ and $40 \mathrm{~min}$ each, excluding an initial 5-min temperature equilibration period.

Prior to Fourier transformation, the free induction decays (FIDs) were zero-filled to $64 \mathrm{k}$ and a $0.3 \mathrm{~Hz}$ line-broadening factor was applied. The chemical shifts are expressed in d scale (ppm), referenced to the residual signal of chloroform. For ${ }^{1} \mathrm{H}$ NMR, this was found at $7.24 \mathrm{ppm}$ [21] whilst for ${ }^{13} \mathrm{C}$ NMR, this was found as a triplet centerd around $77.01 \mathrm{ppm}$ [22]. The corrected spectra were exported as ASCII files from Topspin 3.5 (TopSpin ${ }^{\mathrm{TM}}$ version 5, Bruker, Billerica, MA, USA) and imported directly into The Unscrambler X 10.3 (CAMO Software, Oslo, Norway) for all subsequent mathematical data processing. Each spectrum was automatically binned by the software into 32,768 buckets, each bucket being $0.0072223 \mathrm{ppm}$ wide. The signal-to-noise ratio was calculated using the peak at $172.8 \mathrm{ppm}$ for ${ }^{13} \mathrm{C}$ NMR corresponding to $\mathrm{C} 1$ of the glycerol chain, which resulted in a signal-to-noise ratio of 520:1. For ${ }^{1} \mathrm{H}$ NMR, the signal-to-noise ratio was calculated using the peak at $9.70 \mathrm{ppm}$, corresponding to the aldehyde proton in hexanal, and a signal-to-noise ratio of 1.26:1 and 1.46:1 was obtained for $\mathrm{zg} 30$ and NOESY pulse sequences, respectively.

The spectrum obtained was subjected to different spectroscopic signal processing techniques, which were evaluated and compared. The spectra were normalised, a transformation that put all spectra on the same scale, thus eliminating the fluctuations in intensities between spectra arising from slightly different sample concentrations. Both peak normalisation and area normalisation were carried out separately on the baseline corrected spectrum. Normalisation was followed by detrending and deresolving procedures. The detrend transformation removes the effects of nonlinear trends, showing only the absolute changes in values across spectra by removing the least-squares line of best fit from the data, thus focusing only on fluctuations between data. Deresolve is a noise-reducing transformation that operates by artificially lowering the resolution of the spectra. Other treatments applied to the baseline corrected spectrum include multiplicative and orthogonal scatter corrections (MSC and OSC), and standard normal variate (SNV). MSC was corrected for scaling effects by performing a regression of a spectrum against a reference spectrum, thereby correcting the spectrum using the slope of the 
fit was obtained from the regression. OSC removes variance from the factors that is not related to the response, by finding directions in $\mathrm{X}$ that describe large variances while being orthogonal to $\mathrm{Y}$ and subtracting them from the data. The SNV transformation works similarly to MSC, however, it standardises each spectrum using data from the spectrum itself rather than data averaged from all the spectra. A number of derivatising procedures (1st and 2nd derivatives, Savitzky-Golay) were also carried out. The 1st derivative removes baseline effects while the 2nd derivative also removes the slope of the spectrum by measuring the change in slope, thereby sharpening spectral features. The Savitzky-Golay derivative fits a low-degree polynomial to adjacent points in a spectrum, thereby smoothing the spectrum while minimally affecting the signal-to-noise ratio.

\subsection{Data Analysis}

A principle component analysis (PCA) was carried out using Unscrambler X 10.3 in order to identify any gross outliers and determine any preliminary clustering reflecting the geographical origin. An inspection of the PCA loadings was carried out in order to determine whether the loadings had a spectral shape indicating that observed variation was due to the NMR spectra and not due to noise. PCA was carried out on all treated spectra to reduce all the spectral information down to seven principal components (PCs), which retained the information of the original dataset. The first PC accounted for most of the variation in the dataset, with successive principal components accounting for decreasing amounts of the variation. The resulting PC-1 vs. PC-2 plots could be examined for any clustering that might arise from each spectral pretreatment. Similarly, to PLS, PCA generates loading plots which indicate those $x$-values which are most responsible for the variability between the different spectra. The loading plots for the first two principal components (which explain most of the variability in the dataset) were used to determine which ppm values had the largest influence on the separation of PC-1 and PC-2. Following a PCA, supervised chemometric methods were carried out using JMP ${ }^{\circledR}$, Version 10 (SAS Institute Inc., Cary, NC, USA), including the partial least squares discriminate analysis (PLS-DA). The whole dataset was split into two sets, termed the training and test sets (the former to build the model, the latter to validate it). In order to preserve the diversity in the training and test sets and to account for the fact that different pretreatments had to be tested, a unique sample splitting scheme was used.

In order to determine the suitability of the whole NMR spectra for discrimination of EVOOs of Maltese origin, an artificial neural network (ANN) analysis was carried out. The main advantage of a neural network model is that it can efficiently model different response surfaces due to its nonlinearity, allowing a better fit to the data given enough hidden nodes and layers, providing an accurate prediction for many kinds of data. Unlike other modeling and discriminate methods (PLS) the main disadvantage of a neural network model is that the results are not easily interpretable, due to the presence of several intermediate hidden layers. In this experiment, 25 iterations were carried out using a TanH activation function as the standard neuron activation function in JMP software. In the case of ANN, three different cross-validation techniques were employed in order to prevent model overfitting; the k-fold (CV-10), hold back (33.3\%), and excluded rows (Venetian blinds). Thirty-three percent of the samples were held back from the model during holdback validation, which operates by randomly splitting the dataset into training and validation sets. Thirty-three percent of the data was thus 'held back' to form the validation set. Excluded rows holdback uses those rows that were excluded by the Venetian blinds method as the validation set. K-fold validation divides the dataset into ' $\mathrm{k}$ ' number of subsets where each subset contains a fraction ' $1 / \mathrm{k}^{\prime}$ of the data. Each of these sets is used to validate the model thereby fitting ' $k$ ' number of models. The best fitting model is presented as the final output. In this study, $\mathrm{K}$-fold validation was carried out using $5 \mathrm{k}$-folds. 


\section{Results and Discussion}

\subsection{Geographical Classification of EVOO Using NMR Spectroscopy}

Figure 1 and Table 1 show ${ }^{1} \mathrm{H}$ NMR signals of the major and some minor compounds together with their chemical shifts and their assignments to protons of the different functional groups [10,24-28]. Figure 2 and Table 2 show the major peaks obtained using ${ }^{13} \mathrm{C}$ NMR and identified using the literature $[10,13,14,17,27-33]$.

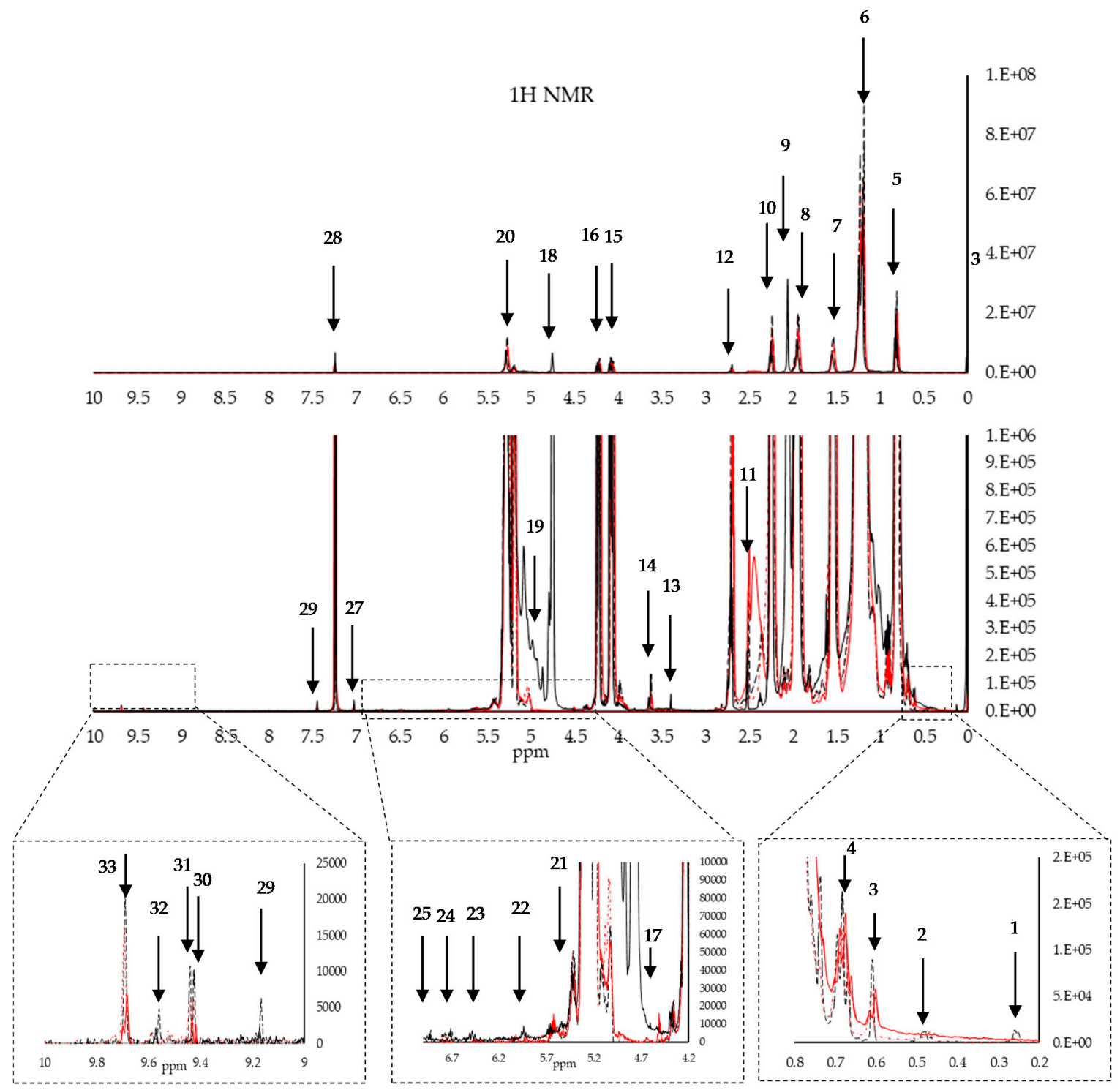

Figure 1. The major peaks of interest obtained from the nuclear magnetic resonance (NMR) of extra virgin olive oils (EVOOs) using the zg30 pulse sequence (black) and NOESY pulse sequence (red). 


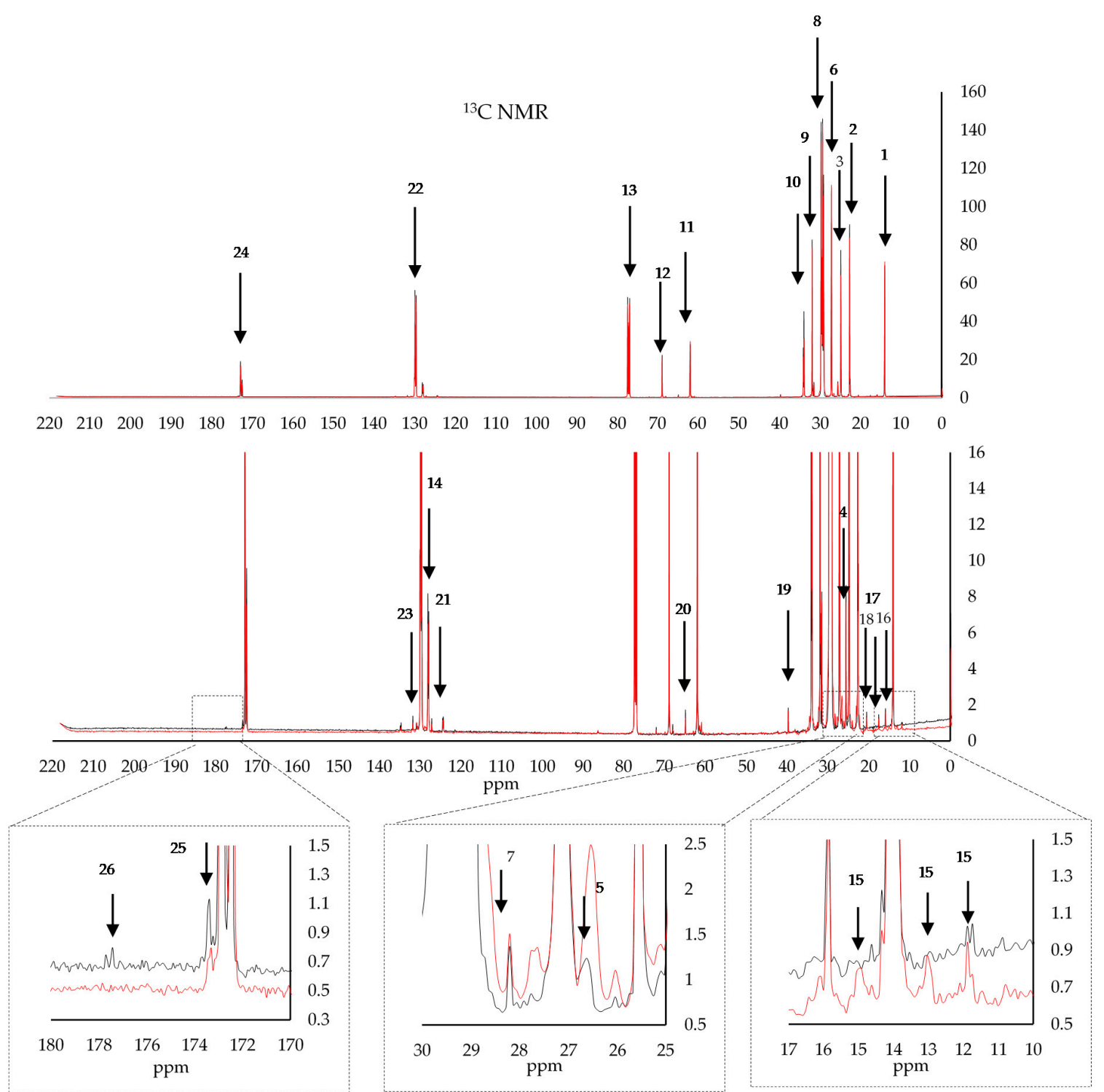

Figure 2. The major peaks of interest obtained using the ${ }^{13} \mathrm{C}$ NMR of EVOOs (black line Maltese EVOOs, red line non-Maltese EVOOs).

Whilst the chemical shifts of the major constituents are well known and easily identified, the ${ }^{1} \mathrm{H}$ and ${ }^{13} \mathrm{C}$ signals of the minor oil components are only observed when their signals do not overlap with those of the main components, and when their concentrations are high enough to be detected [11]. Minor constituents which are expected to yield NMR signals include mono- and diglycerides, sterols, tocopherols, aliphatic alcohols, hydrocarbons, fatty acids, pigments, and phenolic compounds [32]. Figure 1 shows the most common ${ }^{1} \mathrm{H}$ NMR signals of the major and some minor compounds together with their chemical shifts and their assignments to protons of the different functional groups. The main identified compounds include; cycloartenol at 0.29 and $0.54 \mathrm{ppm}, \beta$-sitosterol at $0.62,0.67 \mathrm{ppm}$, stigmasterol at $0.69 \mathrm{ppm}$, wax at $0.98 \mathrm{ppm}$, squalene at $1.66 \mathrm{ppm}, \mathrm{sn}-1,2$ diglyceryl group protons at 3.71 and $5.28 \mathrm{ppm}$, and two unknown terpenes at 4.53, 4.65, and $4.95 \mathrm{ppm}$, hexanal at $9.7 \mathrm{ppm}$, and phenolic protons at, 6.95 , and $6.72 \mathrm{ppm}$. These compounds have already been observed and identified by other authors $[10,11,14,17,30]$. In the case of ${ }^{13} \mathrm{C} N \mathrm{NMR}$, the minor constituents observed were restricted to chemical shifts corresponding to squalene, with a shouldering peak at $26.6 \mathrm{ppm}$ and another minor peak at $28.2 \mathrm{ppm}$ attributed to the allylic methylene group [26]. 
Table 1. Chemical shifts and the corresponding chemical functional group observed for ${ }^{1} \mathrm{H}$ NMR.

\begin{tabular}{|c|c|c|c|c|c|}
\hline \multicolumn{6}{|c|}{${ }^{1} \mathrm{H}$ NMR } \\
\hline & $\begin{array}{l}\text { Chemical } \\
\text { Shift }\end{array}$ & Compound Functional Group & & $\begin{array}{l}\text { Chemical } \\
\text { Shift }\end{array}$ & Compound Functional Group \\
\hline 1 & 0.29 & $\begin{array}{c}-\mathrm{CH}_{2} \text {-(cyclopropanic ring) } \\
\text { cycloartenol }\end{array}$ & 17 & 4.53 & Terpene \\
\hline 2 & 0.54 & $\begin{array}{l}-\mathrm{CH}_{2} \text {-(cyclopropanic ring) } \\
\text { cycloartenol }\end{array}$ & 18 & 4.65 & Terpene \\
\hline 3 & 0.62 & $\begin{array}{c}-\mathrm{CH}_{3}(\mathrm{C} 18 \text {-steroid group }) \\
\beta \text {-sitosterol }\end{array}$ & 19 & 4.95 & Terpene \\
\hline 4 & 0.69 & $\begin{array}{c}-\mathrm{CH}_{3}(\mathrm{C} 18 \text {-steroid group }) \\
\beta \text {-sitosterol }\end{array}$ & 20 & 5.28 & >CHOCOR (glyceryl group) \\
\hline 5 & 0.81 & $-\mathrm{CH}_{3}$ (acyl group) & 21 & 5.55 & Unk 2-Tocopherols \\
\hline 6 & 1.19 & $-\left(\mathrm{CH}_{2}\right) \mathrm{n}$-(acyl group) & 22 & 5.91 & $\begin{array}{l}-\mathrm{CH}=\mathrm{CH}-\mathrm{CH}=\mathrm{CH}-(\mathrm{cis} \text {, trans } \\
\text { conjugated dienediene system) }\end{array}$ \\
\hline 7 & 1.54 & $-\mathrm{OCO}-\mathrm{CH}_{2}-\mathrm{CH}_{2}$-(acyl group) & 23 & 6.56 & $\begin{array}{l}-\mathrm{CH}=\mathrm{CH}-\mathrm{CH}=\mathrm{CH}-(\mathrm{cis} \text {, trans } \\
\text { conjugated dienediene system) }\end{array}$ \\
\hline 8 & 1.95 & $-\mathrm{CH}_{2}-\mathrm{CH}=\mathrm{CH}$-(acyl group) & 24 & 6.72 & -Ph-H (phenolic ring) \\
\hline 9 & 2.08 & $-\mathrm{CH}_{2}-\mathrm{CH}=\mathrm{CH}$-(acyl group) & 25 & 6.95 & -Ph-H (phenolic ring) \\
\hline 10 & 2.26 & $\mathrm{CH}-\mathrm{CH}_{2}-\mathrm{CH}=($ acyl group $)$ & 26 & 7.02 & Chloroform ${ }^{13} \mathrm{C}$ satellite \\
\hline 11 & 2.54 & $\mathrm{CH}-\mathrm{CH}_{2}-\mathrm{CH}=$ (acyl group) satellite & 27 & 7.24 & Chloroform \\
\hline 12 & 2.71 & $\mathrm{CH}-\mathrm{CH}_{2}-\mathrm{CH}=($ acyl group $)$ & 28 & 7.44 & Chloroform ${ }^{13} \mathrm{C}$ satellite \\
\hline 13 & 3.39 & Unk 1-alcohol & 29 & 9.17 & Unk 4-hydrocarbon \\
\hline 14 & 3.71 & $-\mathrm{CH}_{2} \mathrm{OCOR}$ (glyceryl group) & 30 & 9.46 & Unk 5-hydrocarbon \\
\hline 15 & 4.10 & $-\mathrm{CH}_{2} \mathrm{OCOR}$ (glyceryl group) & 31 & 9.47 & Unk 5-hydrocarbon \\
\hline 16 & 4.22 & $-\mathrm{CH}_{2} \mathrm{OCOR}$ (glyceryl group) & $\begin{array}{l}32 \\
33\end{array}$ & $\begin{array}{l}9.58 \\
9.70\end{array}$ & $\begin{array}{c}\text { Unk 6-hydrocarbon } \\
\text { Hexanal }\end{array}$ \\
\hline
\end{tabular}

Table 2. Chemical shifts and the corresponding chemical functional group observed for ${ }^{13} \mathrm{C}$ NMR.

\begin{tabular}{|c|c|c|c|c|c|}
\hline \multicolumn{6}{|c|}{${ }^{13} \mathrm{C}$ NMR } \\
\hline & $\begin{array}{l}\text { Chemical } \\
\text { Shift }\end{array}$ & Compound Functional Group & & Chemical Shift & Compound Functional Group \\
\hline 1 & 14 & $\begin{array}{l}\text { C18( } \omega 1) \text { terminal carbon of } \\
\text { fatty acyl chain }\end{array}$ & 14 & 128.01129 .82 & $\begin{array}{l}\text { C9, C10 oleoyl unsaturated } \\
\text { carbons between } 2-\text { and } 1(3) \text { of } \\
\text { glycerol }\end{array}$ \\
\hline 2 & 22.64 & $\begin{array}{l}\mathrm{C} 17(\omega 2) \text { penultimate carbons } \\
\text { from the fatty acyl chains }\end{array}$ & 15 & $11.97,13.12,14.95$ & $\begin{array}{l}\text { Unk } 1 \text { possibly being attributed to } \\
\text { waxes }\end{array}$ \\
\hline 3 & 24.74 & $\begin{array}{l}\text { C3 methylenic group in } \beta \\
\text { position with respect to the } \\
\text { carbonylic group }\end{array}$ & 16 & 15.95 & $\begin{array}{c}\text { Unk } 2 \text { possibly } \mathrm{C}^{\prime} \text { a and } \mathrm{C}^{\prime} \text { 'a of } \\
\text { tocopherols }\end{array}$ \\
\hline 4 & 25.53 & C11 Linoleyl Linolenyl & 17 & 17.51 & $\begin{array}{l}\text { Unk } 3 \text { possibly } \mathrm{C} 12^{\prime} \text { a of } \\
\text { tocopherols }\end{array}$ \\
\hline 5 & 26.61 & $\begin{array}{l}\text { C8 allylic methylenes of } \\
\text { sqaulene }\end{array}$ & 18 & 20.47 & C17( $\omega 2)$ all acyl chains \\
\hline 6 & 27.12 & $\begin{array}{c}\text { C8 allylic carbons of oleoyl } \\
\text { chains }\end{array}$ & 19 & 39.68 & Unk 4-C1 of tocopherol \\
\hline 7 & 28.6 & $\begin{array}{l}\text { C12 allylic methylenes of } \\
\text { sqaulene }\end{array}$ & 20 & 64.89 & $\begin{array}{c}\text { Unk } 5 \text { possibly C2 of elenolic acid } \\
\text { derivative of tyrosol or } \\
\text { hydroxytyrosol }\end{array}$ \\
\hline 8 & 29.28 & $\begin{array}{l}\text { C4-C7, C12-C15, C8-C15, } \\
\text { C8-C13 methylenic groups in } \\
\text { fatty acid central chain }\end{array}$ & 21 & 124.40 & $\mathrm{C}^{\prime}, \mathrm{C}^{\prime}, \mathrm{C} 11^{\prime}$ of tocopherols \\
\hline 9 & 31.88 & C16 methylenic acylic chains $\omega$ & 22 & 131.70 & $\begin{array}{l}\text { C9 Linoleyl and linolenyl, C13 } \\
\text { Linoleyl }\end{array}$ \\
\hline 10 & 33.91 & $\mathrm{C} 2, \mathrm{sn}-2$ acyl chains & 23 & 134.80 & $\mathrm{C} 4^{\prime}, \mathrm{C} 8^{\prime}$ of tocopherols \\
\hline 11 & 61.93 & $\begin{array}{c}\mathrm{CH}_{2} \mathrm{O}-1(3) \text { glycerol carbons of } \\
\text { triglycerides }\end{array}$ & 24 & 172.8 & C1, sn-2 2-glycerol chain \\
\hline 12 & 68.86 & $\begin{array}{c}\mathrm{CH}_{2} \mathrm{O}-2 \text {-glycerol carbon of } \\
\text { triglycerides resonates }\end{array}$ & 25 & 173.2 & $\begin{array}{c}\text { C1, sn-1,3 } 1(3) \text { glycerol chain } \\
\text { positions }\end{array}$ \\
\hline 13 & 77.39 & $\mathrm{CDCl}_{3}$ Solvent & 26 & 177.92 & Unk $6-\mathrm{COOCH}_{3}$ of elenolic acid \\
\hline
\end{tabular}

The discriminatory models for the traceability of EVOOs from the Maltese islands coupled ${ }^{1} \mathrm{H}$ and ${ }^{13} \mathrm{C}$ NMR spectroscopy with chemometrics. In order to overcome the instrumental limitation and to account for scattering and other minor variations which would hinder the performance of the 
classification model, different kinds of spectral pretreatments were tested and compared. A total of 10 spectral pretreatment methods were used. In each case, after pretreatment, a PCA was carried in order to dimensionally reduce the number of variables into a small set of principal components whilst retaining all the information of the larger set. PCA enabled the preliminary identification of which pretreatment offered the highest variability and possible sample grouping based on the geographical origin but also enabled the identification of outliers and noise modeling.

Figure 3 shows some of the different forms of spectral pretreatments employed and the corresponding PCA plot for the first two principal components. In the case of ${ }^{1} \mathrm{H} N M R$, although clustering was observed in most of the spectral pretreatments, it did not fully discriminate the EVOOs of Maltese origin from those obtained from other Mediterranean countries. Only a weak clustering resembling the geographical origin was observed by using PCA. For ${ }^{1} \mathrm{H}$ NMR, the raw data was presented in Figure 3 as these were seen as the most representative data for highlighting clustering in PCA. Other spectral transformations can be viewed in the Supplementary Materials Figures S1-S3. In the case of ${ }^{13} \mathrm{C} N M R$, the clustering obtained using OSC and SNV spectral transformations highly resembled the geographical origin of EVOO.

A

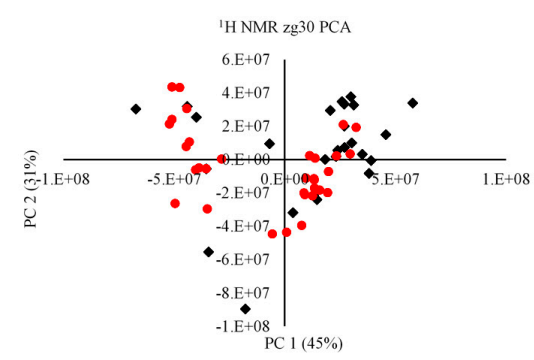

B

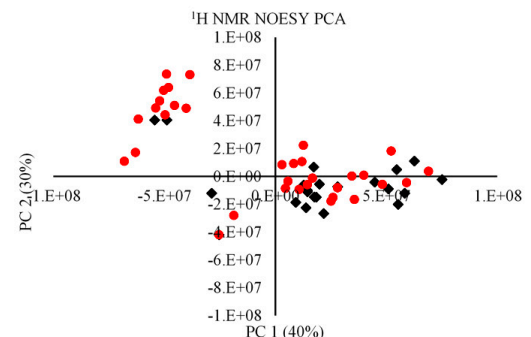

C

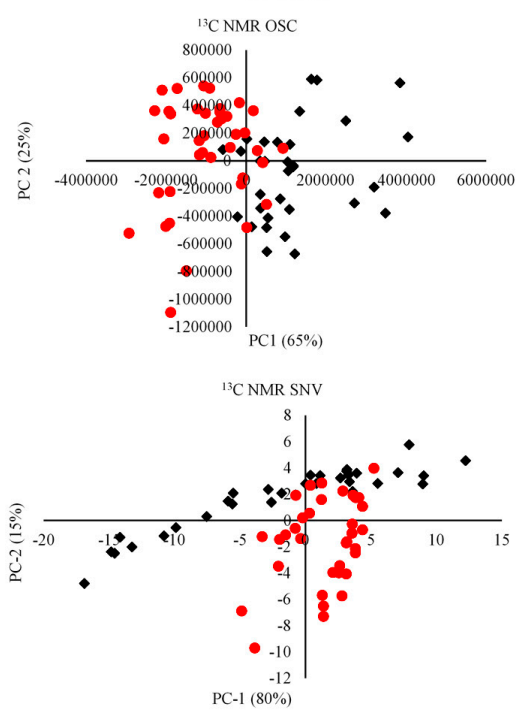

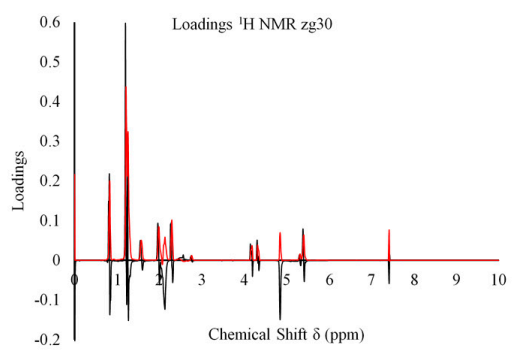
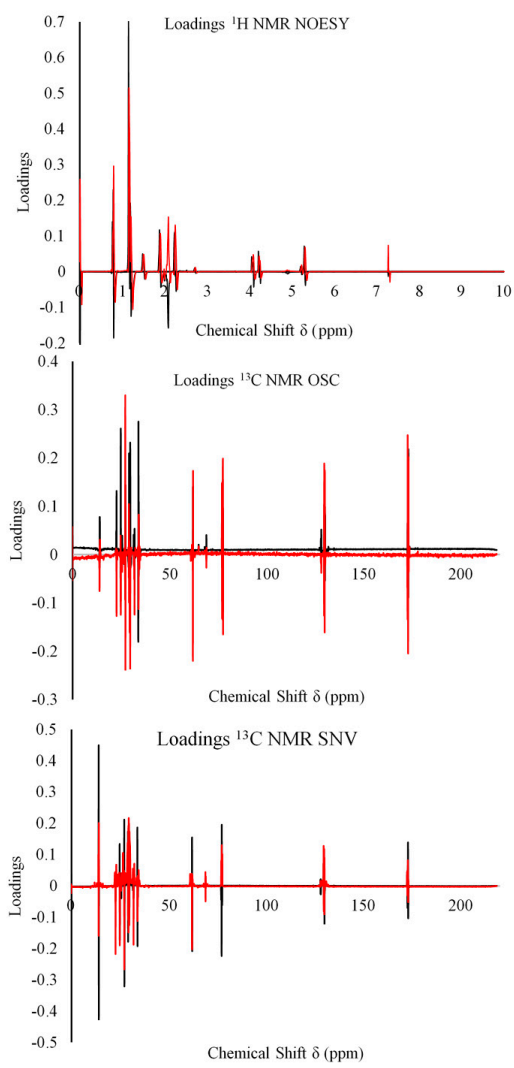

Figure 3. The principle component analysis (PCA) biplots (black boxes = Maltese red dots = non-Maltese) and loading plots for PC1 (black line) and PC2 (red line) for the untreated raw data for the zg30 (A) NOESY (B), ${ }^{13} \mathrm{C}$ NMR orthogonal scatter corrections (OSC) (C), and ${ }^{13} \mathrm{C}$ NMR standard normal variate $(\mathrm{SNV})(\mathrm{D})$ spectra. 
Inspection of the PC loadings revealed a spectral form, which suggests that the variation observed was due to the actual NMR spectra and not due to noise. In the case of zg30, it was observed that the chemical shifts observed at 0.8 and 1.2-1.25 ppm and 0.5-1.25 ppm for the NOESY experiment seem to have a larger influence on the first and second principal component separation. These observations suggest that the phytosterol content, namely $\beta$-sitosterol, campesterol, cycloartenol together with 1-eicosanol and $\alpha$-tocopherol, which show chemical shifts between $0.5-1.25 \mathrm{ppm}$, have a greater influence on the variation observed along the first two principal components. In the case of zg30, other peaks observed in the 4.7-4.9 ppm range also seem to be influential, especially in the 1st PC, these peaks correspond to terpenic compounds present in EVOOs. Alonso-Salces et al., [17,30] identified three peaks at 4.57, 4.65, and $4.70 \mathrm{ppm}$, which were attributed to unknown terpenes during their study on the unsaponifiable fraction of EVOOs. For ${ }^{13} \mathrm{C}$ NMR, inspection of the PC loading plots corresponding to the previously identified chemical shifts were found to offer the most variation, with the peak at $14 \mathrm{ppm}$ assigned to the terminal $-\mathrm{CH}_{3}$ of all acyl chains explaining most of the variation in the SNV spectra.

\subsection{Application of PLS-DA for the Discrimination of Maltese EVOOs}

The Maltese and the non-Maltese samples were grouped in ascending order so that the first 30 samples would represent Maltese EVOOs whilst the rest corresponded to non-Maltese EVOOs. A Venetian blinds cross-validation method was then employed, which selected every sth sample from the data by making data splits such that all samples are left out exactly once $(s=5)$. This sampling method excluded $20 \%$ of the dataset so that they would be retained as the testing set. The remaining $80 \%$ of the dataset was used to build the training set. In the case of PLS-DA, an inspection of the variable importance plot (VIP) scores was carried out. Variables having a smaller VIP than 0.8 were removed, and an adjusted PLS model was built after the removal of these variables. The goodness of fit of the adjusted model was evaluated and compared to the original model. Table 3 shows the accuracy (\% correct classification during training) and the precision (\% correct classification during testing) obtained on using different spectral pretreatments for the two NMR methods. For the zg30 NMR spectra obtained after deresolve, SNV and quantile normalisation showed the best model performance with a $\%$ accuracy ranging from $93.1-87.9 \%$ and $\%$ predictability ranging from $72.7-81.8 \%$, whilst for the NOESY experiment, spectra treated using normalisation and Savitzky-Golay showed the best performance with an accuracy of $94.8 \%$ and predictability of $90.9 \%$. In the case of the zg30 experiment, all the spectral pretreatments showed an improvement in the \% predictability when compared to the raw data, whilst in the NOESY experiment, spectra treated using SNV and detrending functions showed a lower $\%$ predictability and $\%$ accuracy when compared to actual nonpretreated raw data. This observation suggests that, in the case of NOESY, the signal suppression of the major peaks improves the signal to noise ratio, and the resulting spectra can be used without the need of extensive pretreatments. Results obtained by Longobardi et al., [18] showed that the presaturation of the dominating lipid signals resulted in an increased receiver gain which in turn resulted in a signal-to-noise gain close to 10 compared to the zg30 spectra. In the case of ${ }^{13} \mathrm{C} \mathrm{NMR}$, higher rates of accuracy and predictability were observed when compared to ${ }^{1} \mathrm{H}$ NMR methods with a $\%$ predictability ranging from $66.7-100 \%$, with OSC reaching 100\% correct classification in both the training and validation sets. The higher rates of predictability of ${ }^{13} \mathrm{C}$ NMR spectra were attributed to a higher signal-to-noise ratio, less coupling interactions resulting in a cleaner signal, proof of this is the \% predictability of the raw untreated ${ }^{13} \mathrm{C}$ spectra with respect to ${ }^{1} \mathrm{H}$ spectra.

The next step was to build another PLS model, this time using only variables which had a VIP score $>0.8$. Table 3 also shows the results obtained by using the adjusted PLS model for ${ }^{13} \mathrm{C}$ and ${ }^{1} \mathrm{H}$ NMR. An improvement in the overall \% accuracy and predictability of the model. Furthermore, the models obtained using only VIP $>0.8$ variables showed an increase in both $\% \mathrm{X}$ and $\% \mathrm{Y}$ explained, and a higher $\%$ accuracy and \% precision indicating enhanced model performance. In the case of the zg30 experiment, it was found that normalised spectra and Savitzky-Golay derived spectra had the 
optimal performance, whilst detrended and SNV spectra had optimal performance when the whole data set was used. In the case of the NOESY experiment, the models obtained using VIP $>0.8$ showed an increase in the performance when compared to those obtained with whole data.

Table 3. The PLS-DA analysis on both the entire (a) ${ }^{1} \mathrm{H}$ NMR and (b) ${ }^{13} \mathrm{C}$ NMR spectra and selected variables having a VIP $>0.8$ for the different spectral pretreatments. The results obtained on the training dataset are given in terms of $\%$ accuracy of correct classification whilst for the testing data set these are given in terms of \% predictability of correct classification.

\begin{tabular}{|c|c|c|c|c|}
\hline \multicolumn{5}{|c|}{ (a) } \\
\hline \multirow{3}{*}{ Pretreatment } & \multicolumn{4}{|c|}{$\mathrm{zg} 30^{1} \mathrm{H}$ NMR } \\
\hline & \multicolumn{2}{|c|}{ Whole Spectrum } & \multicolumn{2}{|c|}{$\mathrm{VIP}>0.8$} \\
\hline & $\%$ Accuracy & $\%$ Predictability & $\%$ Accuracy & $\%$ Predictability \\
\hline Raw & 77.59 & 27.27 & 82.76 & 45.45 \\
\hline Normalised & 91.38 & 63.64 & 94.83 & 90.91 \\
\hline Q Norm & 93.10 & 72.73 & 94.83 & 72.73 \\
\hline Detrend & 70.69 & 36.36 & 68.97 & 36.36 \\
\hline Deresolve & 87.93 & 63.64 & 82.76 & 45.45 \\
\hline SNV & 93.10 & 81.82 & 60.34 & 36.36 \\
\hline MSC & 91.38 & 81.82 & 67.24 & 63.64 \\
\hline OSC & 72.41 & 45.45 & 94.83 & 72.73 \\
\hline Savitzky-Golay & 74.14 & 54.55 & 98.28 & 90.91 \\
\hline 1st Derivative & 68.97 & 45.45 & 94.83 & 72.73 \\
\hline \multirow[t]{2}{*}{ 2nd Derivative } & 77.59 & 63.64 & 93.10 & 63.64 \\
\hline & \multicolumn{4}{|c|}{ NOESY ${ }^{1} \mathrm{H}$ NMR } \\
\hline \multirow[t]{2}{*}{ Pretreatment } & \multicolumn{2}{|c|}{ Whole Spectrum } & \multicolumn{2}{|c|}{$\mathrm{VIP}>0.8$} \\
\hline & $\%$ Accuracy & $\%$ Predictability & $\%$ Accuracy & $\%$ Predictability \\
\hline Raw & 82.76 & 45.45 & 93.10 & 75.00 \\
\hline Normalised & 94.83 & 90.91 & 94.83 & 83.33 \\
\hline Q Norm & 94.83 & 72.73 & 96.55 & 91.67 \\
\hline Detrend & 68.97 & 36.36 & 74.14 & 66.67 \\
\hline Deresolve & 82.76 & 45.45 & 94.83 & 83.33 \\
\hline SNV & 60.34 & 36.36 & 70.69 & 75.00 \\
\hline MSC & 67.24 & 63.64 & 68.97 & 75.00 \\
\hline OSC & 94.83 & 72.73 & 96.55 & 83.33 \\
\hline Savitzky-Golay & 98.28 & 90.91 & 89.66 & 75.00 \\
\hline 1st Derivative & 94.83 & 72.73 & 93.10 & 91.67 \\
\hline 2nd Derivative & 93.10 & 63.64 & 93.10 & 91.67 \\
\hline \multicolumn{5}{|c|}{ (b) } \\
\hline \multirow{3}{*}{ Pretreatment } & \multicolumn{4}{|c|}{${ }^{13} \mathrm{C}$ NMR } \\
\hline & \multicolumn{2}{|c|}{ Whole Spectrum } & \multicolumn{2}{|c|}{ VIP $>0.8$} \\
\hline & $\%$ Accuracy & $\%$ Predictability & $\%$ Accuracy & $\%$ Predictability \\
\hline Raw & 100.00 & 73.33 & 100.00 & 80.00 \\
\hline Normalised & 100.00 & 86.68 & 94.64 & 100.00 \\
\hline Q Norm & 100.00 & 80.00 & 100.00 & 100.00 \\
\hline Detrend & 100.00 & 66.67 & 100.00 & 100.00 \\
\hline Deresolve & 78.57 & 73.33 & 91.07 & 100.00 \\
\hline SNV & 100.00 & 86.67 & 100.00 & 100.00 \\
\hline MSC & 100.00 & 86.67 & 100.00 & 100.00 \\
\hline OSC & 100.00 & 100.00 & 100.00 & 100.00 \\
\hline Savitzky-Golay & 100.00 & 73.33 & 100.00 & 100.00 \\
\hline 1st Derivative & 100.00 & 80.00 & 100.00 & 100.00 \\
\hline 2nd Derivative & 100.00 & 86.67 & 100.00 & 100.00 \\
\hline
\end{tabular}

These observations indicate that different spectral pretreatments are affected differently to variable selection techniques since each one of them attempts to maximise spectral variations and corrections, therefore, removal of a small number of predictors can have a devastating effect on the model performance. In the case of ${ }^{13} \mathrm{C} N M R$, variable selection greatly improved the discrimination with most of the pretreated spectra reaching $100 \%$ accuracy and predictability. The noticeable increase in the model performance has been attributed to the removal of redundant variables which correct for overfitting by excluding noise variables from the data, therefore, preventing them from affecting 
the model. Reducing the number of variables around which the model is built also increases the model's reliability.

\subsection{Whole ${ }^{1} \mathrm{H}$ and ${ }^{13} \mathrm{C}-\mathrm{NMR}$ Modeling Using Feed-Forward Predictive Artificial Neural Networks}

The use of feed-forward predictive neural networks on the NMR data as a method for classification was assessed using three different forms of validation, namely $33.3 \%$ data holdback, CV-10 k-fold, and excluded row validation. Since ANNs are more powerful than any other classification method in terms of their flexibility and noise insensitivity, the algorithm was fitted on the training set using the entire NMR spectrum without any form of variable selection. Table $4 a, b$ shows $\%$ accuracy and $\%$ predictability for the different forms of cross-validation carried out on different spectral pretreatments of ${ }^{13} \mathrm{C}$ NMR and ${ }^{1} \mathrm{H}$ NMR under the zg30 and NOESY NMR spectra. In general, contrary to what was observed in PLS-DA, it was observed that models obtained under ${ }^{1} \mathrm{H}$ NMR models had higher rates of classification when compared to ${ }^{13} \mathrm{C}$ NMR. Similarly, to what was observed in PLS-DA, raw data derived from the NOESY experiment had a higher model performance throughout the three different validation methods used when compared to the $\mathrm{zg} 30$ experiment. With respect to validation it was observed that, irrelevant to the spectrum used, the $33 \%$ holdback cross-validation resulted in overfitted models which were identified as spectral transformations that had very good training models but failed to predict new samples with the exception of MSC. In general, the best performing cross-validation method was the excluded row validation followed by k-fold validation. This could be attributed to the fact that these cross-validation methods are not completely random as the $33 \%$ holdback. In the case of the excluded row validation the samples were selected in such a way that, the groups contained approximately equal amounts of local and foreign EVOOs in the training stage. Thus, the models obtained where equally capable of recognising and predicting local and foreign EVOOs.

Table 4. Application of artificial neural network (ANN) on the (a) ${ }^{1} \mathrm{H}$ NMR and (b) ${ }^{13} \mathrm{C}$ NMR data using three forms of cross-validation.

\begin{tabular}{|c|c|c|c|c|c|c|}
\hline \multicolumn{7}{|c|}{ ANN } \\
\hline \multirow{2}{*}{ Pretreatment } & \multicolumn{2}{|c|}{ Holdback } & \multicolumn{2}{|c|}{ CV-10 } & \multicolumn{2}{|c|}{ Excluded Row } \\
\hline & Training & Validation & Training & Validation & Training & Validation \\
\hline \multicolumn{7}{|c|}{ (a) } \\
\hline \multicolumn{7}{|c|}{ zg30 ${ }^{1} \mathrm{H}$ NMR } \\
\hline Raw & 81.03 & 81.82 & 96.55 & 81.82 & 86.21 & 90.91 \\
\hline Normalised & 94.83 & 81.82 & 94.83 & 100 & 81.03 & 63.64 \\
\hline Q Norm & 98.28 & 90.91 & 98.28 & 90.91 & 82.76 & 81.82 \\
\hline Detrend & 77.59 & 54.55 & 91.38 & 90.91 & 75.86 & 45.45 \\
\hline Deresolve & 91.38 & 90.91 & 93.1 & 90.91 & 79.31 & 81.82 \\
\hline SNV & 96.55 & 90.91 & 98.28 & 100.00 & 74.14 & 72.73 \\
\hline MSC & 98.28 & 100.00 & 96.55 & 90.91 & 93.10 & 90.91 \\
\hline OSC & 77.59 & 36.36 & 89.66 & 63.64 & 84.48 & 81.82 \\
\hline 2nd Derivative & 96.55 & 90.91 & 98.28 & 100.00 & 86.21 & 45.45 \\
\hline 1st Derivative & 84.48 & 90.91 & 98.28 & 90.91 & 81.03 & 63.64 \\
\hline Savitzky-Golay & 91.38 & 81.82 & 98.28 & 90.91 & 85.00 & 90.91 \\
\hline \multicolumn{7}{|c|}{ NOESY ${ }^{1} \mathrm{H}$ NMR } \\
\hline Raw & 93.33 & 91.67 & 93.33 & 91.67 & 93.33 & 91.67 \\
\hline Normalised & 95.00 & 91.67 & 95.00 & 100.00 & 93.33 & 100.00 \\
\hline Q Norm & 98.33 & 100.00 & 98.33 & 100.00 & 93.33 & 100.00 \\
\hline Detrend & 70.00 & 83.33 & 96.67 & 91.67 & 95.00 & 83.33 \\
\hline Deresolve & 96.67 & 100.00 & 96.67 & 100.00 & 91.67 & 83.33 \\
\hline SNV & 93.33 & 91.67 & 98.33 & 100.00 & 98.33 & 100.00 \\
\hline MSC & 93.33 & 100.00 & 93.33 & 83.33 & 95.00 & 91.67 \\
\hline OSC & 81.67 & 75.00 & 91.67 & 75.00 & 90.00 & 91.67 \\
\hline 2nd Derivative & 96.67 & 100 & 98.33 & 100.00 & 96.67 & 91.67 \\
\hline 1st Derivative & 93.33 & 91.67 & 98.33 & 100.00 & 93.33 & 100.00 \\
\hline Savitzky-Golay & 88.33 & 100 & 98.33 & 100.00 & 90.00 & 91.67 \\
\hline
\end{tabular}


Table 4. Cont.

\begin{tabular}{|c|c|c|c|c|c|c|}
\hline \multicolumn{7}{|c|}{ ANN } \\
\hline \multirow{2}{*}{ Pretreatment } & \multicolumn{2}{|c|}{ Holdback } & \multicolumn{2}{|c|}{ CV-10 } & \multicolumn{2}{|c|}{ Excluded Row } \\
\hline & Training & Validation & Training & Validation & Training & Validation \\
\hline \multicolumn{7}{|c|}{ (b) } \\
\hline \multicolumn{7}{|c|}{${ }^{13} \mathrm{C}$ NMR } \\
\hline Raw & 83.93 & 60.00 & 100.00 & 80.00 & 92.62 & 80.00 \\
\hline Normalised & 91.07 & 46.67 & 100.00 & 100.00 & 100.00 & 100.00 \\
\hline Q Norm & 78.57 & 80.00 & 98.21 & 86.67 & 98.21 & 100.00 \\
\hline Detrend & 91.07 & 80.00 & 100.00 & 80.00 & 98.21 & 86.67 \\
\hline Deresolve & 78.57 & 73.33 & 100.00 & 40.00 & 87.50 & 86.67 \\
\hline SNV & 94.64 & 86.67 & 98.21 & 93.33 & 92.86 & 100.00 \\
\hline MSC & 80.36 & 53.33 & 100.00 & 73.33 & 100.00 & 86.67 \\
\hline OSC & 75.00 & 66.67 & 75.00 & 66.67 & 100.00 & 73.33 \\
\hline 2nd Derivative & 85.71 & 40.00 & 100.00 & 66.67 & 96.43 & 86.67 \\
\hline 1st Derivative & 94.64 & 73.33 & 100.00 & 46.67 & 100.00 & 73.33 \\
\hline Savitzky-Golay & 83.93 & 40.00 & 100.00 & 73.33 & 83.93 & 93.33 \\
\hline
\end{tabular}

\section{Conclusions}

It was shown that different NMR methods in conjunction with chemometric methods provided a new insight in the identification of Maltese EVOOs. From the preliminary assessment using only unsupervised PCA models, no significant clustering was observed, and this was attributed to the high levels of similarity between the two classes of EVOOs studied, therefore, this method was deemed to be unsatisfactory when it comes to discrimination of geographical origin. The application of supervised methods of classification, namely PLS-DA and ANN, were shown to be highly effective in discriminating local and nonlocal EVOO samples. The use of the variable selection methods significantly increased the effectiveness of PLS-DA models in discriminating Maltese EVOOs. ANN models were also shown to offer similar classification rates to PLS-DA models and thus they corroborate the results obtained. Results showed that different NMR pulse methods can greatly affect the discrimination of EVOOs. The most informative method was ${ }^{13} \mathrm{C}$ NMR, which resulted in a cleaner spectrum which was void of coupling, followed by the ${ }^{1} \mathrm{H}$ NOESY pulse sequence, in which suppression of strong signals greatly improved the signal-to-noise ratio when compared to the $\mathrm{zg} 30^{1} \mathrm{H}$ NMR spectra. NMR data acquired using the zg30 pulse sequence required an extensive spectral elaboration in order to obtain a comparable model performance to that of ${ }^{1} \mathrm{H}$ NOESY and ${ }^{13} \mathrm{C}$ NMR. It was concluded that apart from the initial and running costs of the instrumentation, NMR proved to be a cheap and reliable technique for the discrimination of Maltese EVOOs from non-Maltese EVOOs. Whilst ${ }^{13} \mathrm{C}$ NMR was very successful in the discrimination of Maltese EVOOs, the long acquisition time proved to be unsatisfactory for a high throughput analysis and thus it is proposed to be used as a confirmatory method for the identification of origin.

Supplementary Materials: The following are available online at http://www.mdpi.com/2304-8158/9/6/689/s1, Table S1: The cultivars used in this study and their country of origin. Figure S1. The principle component analysis and loading plots for different ${ }^{13} \mathrm{C}$ NMR spectra. Figure S2. The principle component analysis biplots and loading plots for different ${ }^{1} \mathrm{H}$ zg30 NMR spectra. Figure S3. The principle component analysis biplots and loading plots for different ${ }^{1} \mathrm{H}$ NOESY NMR spectra.

Author Contributions: F.L., data acquisition, research paper conceptualisation, methodology, software, validation, formal analysis, investigation, data curation, writing — original draft preparation, writing — review and editing, and funding acquisition; B.V., data acquisition, methodology, software, validation, writing-review and editing; M.Z.M., conceptualisation, writing — original draft preparation, writing — review and editing, and supervision; C.F., conceptualisation, software, writing - original draft preparation, formal analysis supervision, and project administration. All authors have read and agreed to the published version of the manuscript.

Funding: This research was funded by the Malta Government Scholarships Post-Graduate Scheme for 2014 (MGSS-PG 2014).

Acknowledgments: Robert Borg for his constant support and training on the NMR spectrometer present at the University of Malta. 
Conflicts of Interest: The authors declare no conflict of interest.

\section{References}

1. European Community Commission Regulation (EEC) no. 2568/1991 on the characteristics of olive and olive pomace oils and their analytical methods. Off. J. Eur. Communities 1991, L248, 1-83.

2. International Olive Council (IOC). Trade Standard Applying to Olive Oils and Olive-Pomace Oils, COI/T.15/NC No. 3/Rev 6. 2011. Available online: http://www.internationaloliveoil.org (accessed on 11 February 2020).

3. Ceci, L.N.; Carelli, A.A. Relation between oxidative stability and composition in Argentinian olive oils. J. AOCS 2010, 87, 1189-1197. [CrossRef]

4. Frankel, E.N. Chemistry of extra virgin olive oil: Adulteration, oxidative stability, and antioxidants. J. Agric. Food Chem. 2010, 58, 5991-6006. [CrossRef] [PubMed]

5. Canabate-Diaz, B.; Segura Carretero, A.; Fernandez-Gutierrez, A.; Belmonte Vega, A.; Garrido Frenich, A.; Martinez Vidal, J.L. Separation and determination of sterols in olive oil by HPLC-MS. Food Chem. 2007, 102, 593-598. [CrossRef]

6. Murkovic, M.; Lechmer, S.; Pietzka, A.; Bratacos, M.; Katzoiamnos, E. Analysis of minor components in olive oil. J. Biochem. Biophys. Methods 2004, 61, 155-160. [CrossRef]

7. Suárez, M.; Macià, A.; Romero, M.P.; Motilva, M.J. Improved liquid chromatography tandem mass spectrometry method for the determination of phenolic compounds in virgin olive oil. J. Chromatogr. A 2008, 1214, 90-99. [CrossRef]

8. Morales, M.T.; Luna, G.; Aparicio, R. Comparative study of virgin olive oil sensory defects. Food Chem. 2005, 91, 293-301. [CrossRef]

9. Vlahov, G. Application of NMR to the study of olive oils. Prog. Nucl. Magn. Reson. Spectrosc. 1999, 35, 341-357. [CrossRef]

10. Sacchi, R.; Patumi, M.; Fontanazza, G.; Barone, P.; Fiordiponti, P.; Mannina, L.; Segre, A.L. A high-field ${ }^{1} \mathrm{H}$ nuclear magnetic resonance study of the minor components in virgin olive oils. J. AOCS 1996, 23, 747-758.

11. Guillen, M.D.; Ruiz, A. High resolution ${ }^{1} \mathrm{H}$ nuclear magnetic resonance in the study of edible oils and fats. Trends Food Sci. Technol. 2001, 12, 328-338. [CrossRef]

12. Hidalgo, F.J.; Gómez, G.; Navarro, J.L.; Zamora, R. Oil stability prediction by high-resolution ${ }^{13} \mathrm{C}$ nuclear magnetic resonance spectroscopy. J. Agric. Food Chem. 2002, 50, 5825-5831. [CrossRef] [PubMed]

13. Mannina, L.; Marini, F.; Gobbino, M.; Sobolev, A.P.; Capitani, D. NMR and chemometrics in tracing European olive oils: The case study of Ligurian samples. Talanta 2010, 80, 2141-2148. [CrossRef] [PubMed]

14. Mannina, L.; Patumi, M.; Proietti, N.; Bassi, D.; Segre, A.L. Geographical characterization of Italian extra virgin olive oils using high field ${ }^{1} \mathrm{H}-\mathrm{NMR}$ spectroscopy. J. Agric. Food Chem. 2001, 49, 2687-2696. [CrossRef] [PubMed]

15. Spyros, A.; Dais, P. Application of ${ }^{31} \mathrm{P}$ NMR spectroscopy in food Analysis, Quantitative determination of the mono- and di-glyceride composition of olive oils. J. Agric. Food Chem. 2000, 48, 802-805. [CrossRef] [PubMed]

16. Rezzi, S.; Axelson, D.E.; Heberger, K.; Reniero, F.; Mariani, C.; Guillou, C. Classification of olive oils using high throughput flow ${ }^{1} \mathrm{H}-\mathrm{NMR}$ fingerprinting with principal component analysis, linear discriminant analysis and probabilistic neural networks. Anal. Chim. Acta 2005, 55, 13-24. [CrossRef]

17. Alonso-Salces, R.M.; Héberger, K.; Holland, M.V.; Moreno-Rojas, J.M.; Mariani, C.; Bellan, G.; Guillou, C. Multivariate analysis of NMR fingerprint of the unsaponifiable fraction of virgin olive oils for authentication purposes. Food Chem. 2010, 118, 956-965. [CrossRef]

18. Longobardi, F.; Ventrella, A.; Napoli, C.; Humpfer, E.; Schütz, B.; Schäfer, H.; Sacco, A. Classification of olive oils according to geographical origin by using ${ }^{1} \mathrm{H}$ NMR fingerprinting combined with multivariate analysis. Food Chem. 2012, 130, 177-183. [CrossRef]

19. Preedy, V.R.; Watson, R.R. Olives and Olive Oil in Health and Disease Prevention; Elsevier Academic Press: Amsterdam, The Netherlans, 2010.

20. Lia, F.; Farrugia, C.; Zammit-Mangion, M. Application of Elemental Analysis via Energy Dispersive X-Ray Fluorescence (ED-XRF) for the Authentication of Maltese Extra Virgin Olive Oil. Agriculture 2020, 10, 71. [CrossRef] 
21. Lia, F.; Farrugia, C.; Zammit-Mangion, M. A First Description of the Phenolic Profile of EVOOs from the Maltese Islands Using SPE and HPLC: Pedo-Climatic Conditions Modulate Genetic Factors. Agriculture 2019, 9, 107. [CrossRef]

22. Lia, F.; Formosa, J.P.; Zammit-Mangion, M.; Farrugia, C. The First Identification of the Uniqueness and Authentication of Maltese Extra Virgin Olive Oil Using 3D-Fluorescence Spectroscopy Coupled with Multi-Way Data Analysis. Foods 2020, 9, 498. [CrossRef]

23. Merchak, N.; Bacha, E.L.; Bou Khouzam, R.; Rizk, T.; Akoka, S.; Bejjani, J. Geoclimatic, morphological, and temporal effects on Lebanese olive oils composition and classification: A ${ }^{1} \mathrm{H}$ NMR metabolomic study. Food Chem. 2017, 217, 379-388. [CrossRef] [PubMed]

24. Hoffman, R.E. Standardization of chemical shifts of TMS and solvent signals in NMR solvents. Magn. Reson. Chem. 2006, 44, 606-616. [CrossRef] [PubMed]

25. Sacchi, R.; Addeo, F.; Paolillo, L. ${ }^{1} \mathrm{H}$ and ${ }^{13} \mathrm{C}$ NMR of virgin olive oil. An overview. Magn. Reson. Chem. 1997, 35, 133-145. [CrossRef]

26. Nam, A.; Bighelli, A.; Tomi, F. Quantification of Squalene in Olive Oil Using ${ }^{13} \mathrm{C}$ Nuclear Magnetic Resonance Spectroscopy. Magnetochemistry 2017, 3, 34. [CrossRef]

27. Sacco, A.; Brescia, M.A.; Liuzzi, V.; Reniero, F.; Guillou, C.; Ghelli, S.; van der Meer, P. Characterization of Italian olive oils based on analytical and nuclear magnetic resonance determinations. JAOCS 2000, 77, 619-625. [CrossRef]

28. Vlahov, G.; Del Re, P.; Simone, N. Determination of geographical origin of olive oils using ${ }^{13} \mathrm{C}$ nuclear magnetic resonance spectroscopy. I-Classification of olive oils of the Puglia region with denomination of protected origin. J. Agric. Food Chem. 2003, 51, 5612-5615. [CrossRef]

29. Shaw, A.D.; di Camillo, A.; Vlahov, G.; Jones, A. Discrimination of the variety and region of origin of extra virgin olive oil using ${ }^{13} \mathrm{C}$ NMR and multivariate calibration with variable reduction. Anal. Chim. Acta 1997, 348, 357-374. [CrossRef]

30. Alonso-Salces, R.M.; Moreno-Rojas, J.M.; Holland, M.V.; Reniero, F.; Guillou, C.; Heberger, K. Virgin Olive Oil Authentication by Multivariate Analyses of ${ }^{1} \mathrm{H}$ NMR Fingerprints and ${ }^{13} \mathrm{C}$ and ${ }^{2} \mathrm{H}$ Data. J. Agric. Food Chem. 2010, 58, 5586-5596. [CrossRef]

31. McKenzie, J.M.; Koch, K.R. Rapid analysis of major components and potential authentication of South African olive oils by quantitative ${ }^{13}$ C nuclear magnetic resonance. S. Afr. J. Sci. 2004, 100, 349-354.

32. Harwood, J.L.; Aparicio, R. Handbook of Olive Oil: Analysis and Properties; Aspen. Henna: Gaithersburg, MD, USA, 2000.

33. D'Imperio, M.; Dugo, G.; Alfa, M.; Mannina, L.; Segre, A.L. Statistical analysis on Sicilian olive oils. Food Chem. 2007, 102, 956-965. [CrossRef]

(C) 2020 by the authors. Licensee MDPI, Basel, Switzerland. This article is an open access article distributed under the terms and conditions of the Creative Commons Attribution (CC BY) license (http://creativecommons.org/licenses/by/4.0/). 